\title{
MODELO NUMÉRICO DE FLUXO DE UM AQUÍFERO \\ CÁRSTICO-FISSURAL EM SÃO FRANCISCO, MG, UTILIZANDO O MODELO HYDROGEOSPHERE
}

\author{
NUMERICAL FLOW MODEL IN STEADY STATE OF A \\ KARST-FISSURE AQUIFER IN SÃO FRANCISCO, MG, USING \\ THE HYDROGEOSPHERE MODEL
}

\author{
Stela Dalva Santos Cota $^{1}$; Guilherme F. Marques ${ }^{2}$; Leila M. Velásquez ${ }^{3}$; Paulo C. Rodrigues ${ }^{1}$
}

Artigo recebido em: 27/02/2012 e aceito para publicação em: 14/06/2012

\begin{abstract}
The pursue of a better understanding of the hydrological behavior of a regional karst-fissure system is the first step towards an adequate management of its scarce water resources. The groundwater flow computational modeling is an excellent tool for this task. This paper goal is to describe the flow in the aquifers belonging to the karstfissure system of the Mocambo creek watershed, São Francisco municipality, MG, Brazil, applying the equivalent porous media approach, by employing the HydroGeoSphere model. The steady-state model was calibrated using the potenciometric data for April/2009 and April/2010, and the groundwater flow discharge to the creeks. The calibrated values for the hydraulic conductivities of the superior carbonate aquifer, the aquitard and the inferior carbonate aquifer are $6.10^{-2}, 8.10^{-6}$ and $1.10^{-2} \mathrm{~m} / \mathrm{h}$, respectively, and the main recharge, applied to the superior carbonate aquifer, corresponds to $35 \%$ of the estimated water surplus. The results showed that it is possible to simulate the groundwater flow in a karst-fissure system using the equivalent porous media approach, provided that the system behaves as expected for a pore system.
\end{abstract}

Keywords: Computational simulation. Equivalent porous media. Flow model.

Resumo: Compreender melhor o comportamento hidrológico do sistema cárstico regional é o primeiro passo para subsidiar políticas públicas adequadas para o bom uso de suas escassas reservas hídricas. A modelagem computacional do fluxo subterrâneo é uma excelente ferramenta para essa tarefa. O objetivo deste trabalho foi descrever o fluxo nos aquíferos que compõem o sistema cárstico-fissural da bacia do riacho Mocambo, município de São Francisco, MG, aplicando uma abordagem de meio poroso equivalente, utilizando o modelo HydroGeoSphere. O modelo em regime permanente foi calibrado com base nos dados potenciométricos de abril/2009 e abril/2010 e do aporte subterrâneo para rios. Os valores de condutividade hidráulica calibrados foram de $6.10^{-2}, 8.10^{-6}$ e $1.10^{-2} \mathrm{~m} / \mathrm{h}$ para o aquífero carbonático superior, o aquitardo e o aquífero carbonático inferior, respectivamente, e a recarga principal, aplicada no topo do aquífero carbonático superior, correspondente a $35 \%$ do excedente hídrico. Os resultados obtidos indicam ser possível simular um sistema de fluxo subterrâneo cárstico-fissural adotando-se a abordagem de meio poroso equivalente, desde que haja um comportamento geral do sistema de acordo com o esperado para um sistema poroso.

Palavras Chave: Simulação computacional. Meio poroso equivalente. Modelo de fluxo.

\section{INTRODUÇÃO}

O Sistemas cársticos são caracterizados por apresentarem condutos gerados por dissolução de rochas calcárias ou carbonáticas, onde a circulação da água se faz nas fraturas alargadas e dutos. O clássico fluxo laminar dos sistemas porosos, caracterizados pela Lei de Darcy, pode, portanto, não ser encontrado nesses sistemas (FREEZE e CHERRY, 1979). Segundo White (2007), o tamanho de abertura das fraturas que estabelee o limite entre as permeabilidades encontradas em sistemas fraturados e cársticos é da ordem de um centímetro.

Em razão da característica intermitente das águas superficiais em regiões de clima semi-árido, esses sistemas podem se constituir importantes componentes da hidrologia regional como fontes de abastecimento de água. Apesar das dificuldades naturais de se mapearem e estudarem esses sistemas altamente heterogêneos, compreender seu comportamento e as respostas de intervenções

\footnotetext{
${ }^{1}$ Centro de Desenvolvimento da Tecnologia Nuclear - CDTN/CNEN (stelacota@gmail.com; e pchr@cdtn.br)

${ }^{2}$ Centro Federal de Educação Tecnológica de Minas Gerais - CEFET-MG (gmarques@ civil.cefetmg.br)

${ }^{3}$ Universidade Federal de Minas Gerais - IGC/UFMG, MG (menegase@ yahoo.com.br)
} 
antrópicas é o primeiro passo para assegurar o uso sustentável das reservas e a disponibilidade futura da água. E, para compreender e quantificar essas reservas, a modelagem do fluxo subterrâneo é uma importante ferramenta a ser empregada.

White (2007) apresenta um histórico de 40 anos de estudos de sistemas cársticos, incluindo a evolução das técnicas utilizadas na sua caracterização e as possibilidades na elaboração de um modelo matemático de fluxo. Segundo o autor, as possíveis abordagens de modelagem de fluxo podem variar de acordo com o maior ou menor foco na hidráulica de meios porosos.

Uma das abordagens mais utilizadas, a do meio poroso equivalente, implica no uso de modelos matemáticos desenvolvidos para sistemas porosos na descrição de sistemas altamente heterogêneos como os cársticos, sendo sua validade limitada a escalas pequenas o suficiente para que as heterogeneidades possam ser representadas através de valores médios de condutividades hidráulicas. Scanlon et al. (2003) utilizaram o modelo MODFLOW (McDONALD e HARBAUGH, 1988) para representação do aquífero regional cárstico Edwards, no Texas, EUA, com uma área de cerca de $330 \mathrm{~km}^{2}$. Também utilizando MODFLOW, Quinn et al. (2006) introduziram a condição de contorno tipo Dreno para simular os condutos de uma área de $150 \mathrm{~km}^{2}$ do sistema cárstico da Formação Malm, Hohenfels, Alemanha. Em uma área ainda maior $\left(21.000 \mathrm{~km}^{2}\right)$, Gondwe et al. (2011) utilizaram a mesma abordagem para estudar a incerteza na elaboração de modelos conceituais em um aquífero cárstico na Penísula de Yucatan, México.

Em outra ponta de raciocínio, há os chamados modelos "black-box" ou "lumped parameter", envolvendo a calibração de parâmetros sem significado físico, que requerem menos informações sobre a área (INTERNATIONAL ATOMIC ENERGY AGENCY - IAEA, 2001). Barrett e Charbeneau (1997) aplicaram esse conceito ao mesmo aquífero cárstico Edwards e utilizaram cinco reservatórios representando as sub-bacias dos cinco principais riachos que atravessam a área e que recarregam o aquífero, sendo que o fluxo entre eles foi simulado considerando a lei de Darcy.

O presente artigo apresenta a aplicação de uma abordagem de meio poroso equivalente para descrever matematicamente o fluxo nos aquíferos que compõem o sistema cárstico-fissural da bacia do riacho Mocambo, município de São Francisco, norte de Minas Gerais. Na elaboração do modelo de fluxo foi utilizado o modelo HydroGeoSphere (TERRIEN et al., 2009). O modelo conceitual, base para a elaboração do modelo numérico de fluxo, foi elaborado através de caracterização geológica, hidrogeológica e hidrológica da bacia em estudo, conduzidas em 2009 e 2010. O modelo foi calibrado com base em dados de potenciometria obtidos em abril/2009 (final da estação chuvosa) e medidas de vazão nos córregos da região.

\section{CARACTERIZAÇÃO GERAL DA ÁREA DE ESTUDO}

Este estudo foi desenvolvido na bacia do riacho Mocambo, localizado na parte sul do município de São Francisco (Figura 1), região norte do estado de Minas Gerais, porção média da bacia do rio São Francisco. A cidade sede homônima

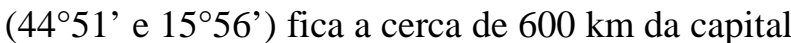
mineira, Belo Horizonte. A bacia escolhida, com aproximadamente $360 \mathrm{~km}^{2}$, é constituída pelas sub-bacias dos riachos Mocambo, Tabocal, Pageú, Várzea de Casa e Tinguis (Figura 2). 


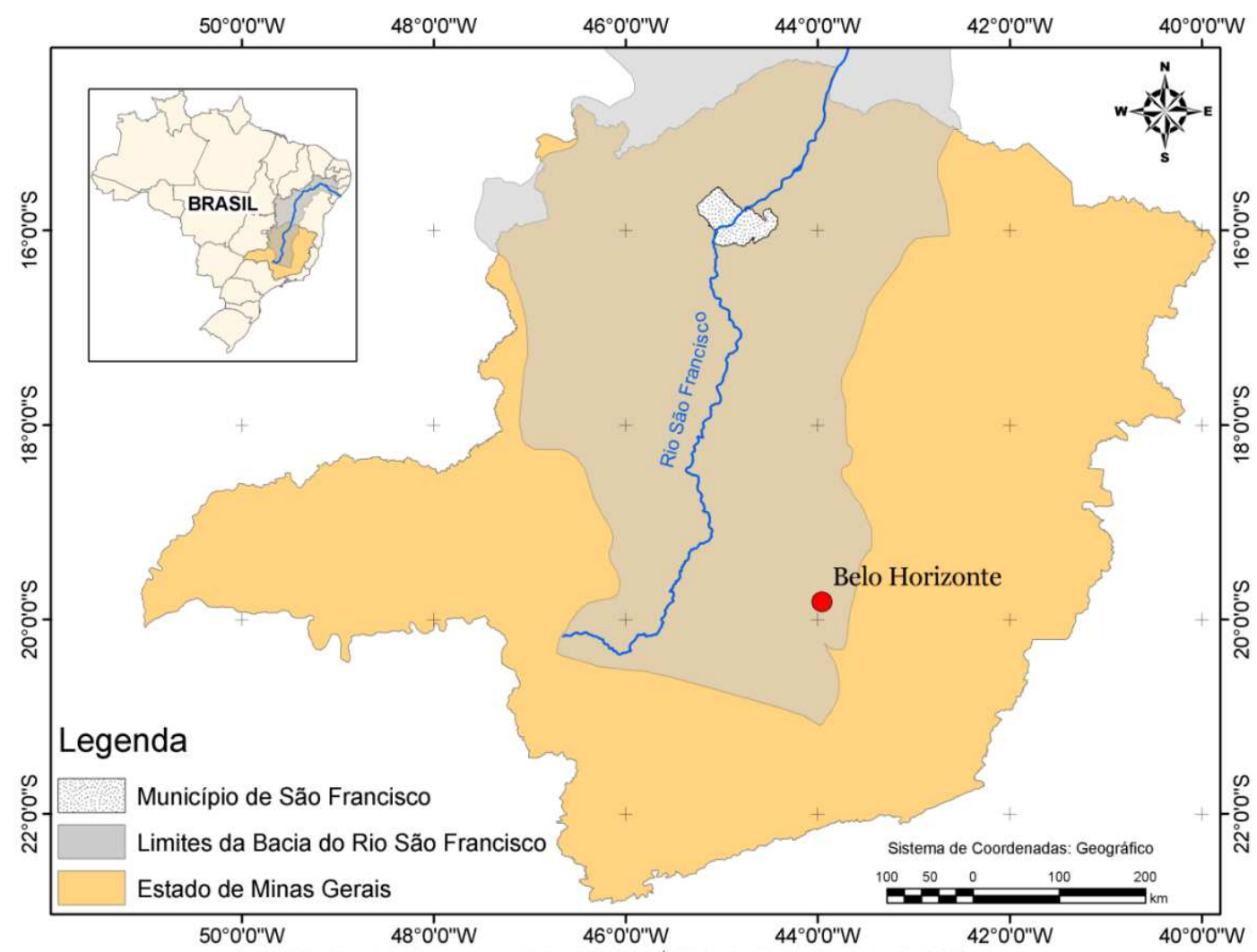

Figura 1 - Mapa de localização da área de estudo.

Figure 1 - Location map of the area of study.

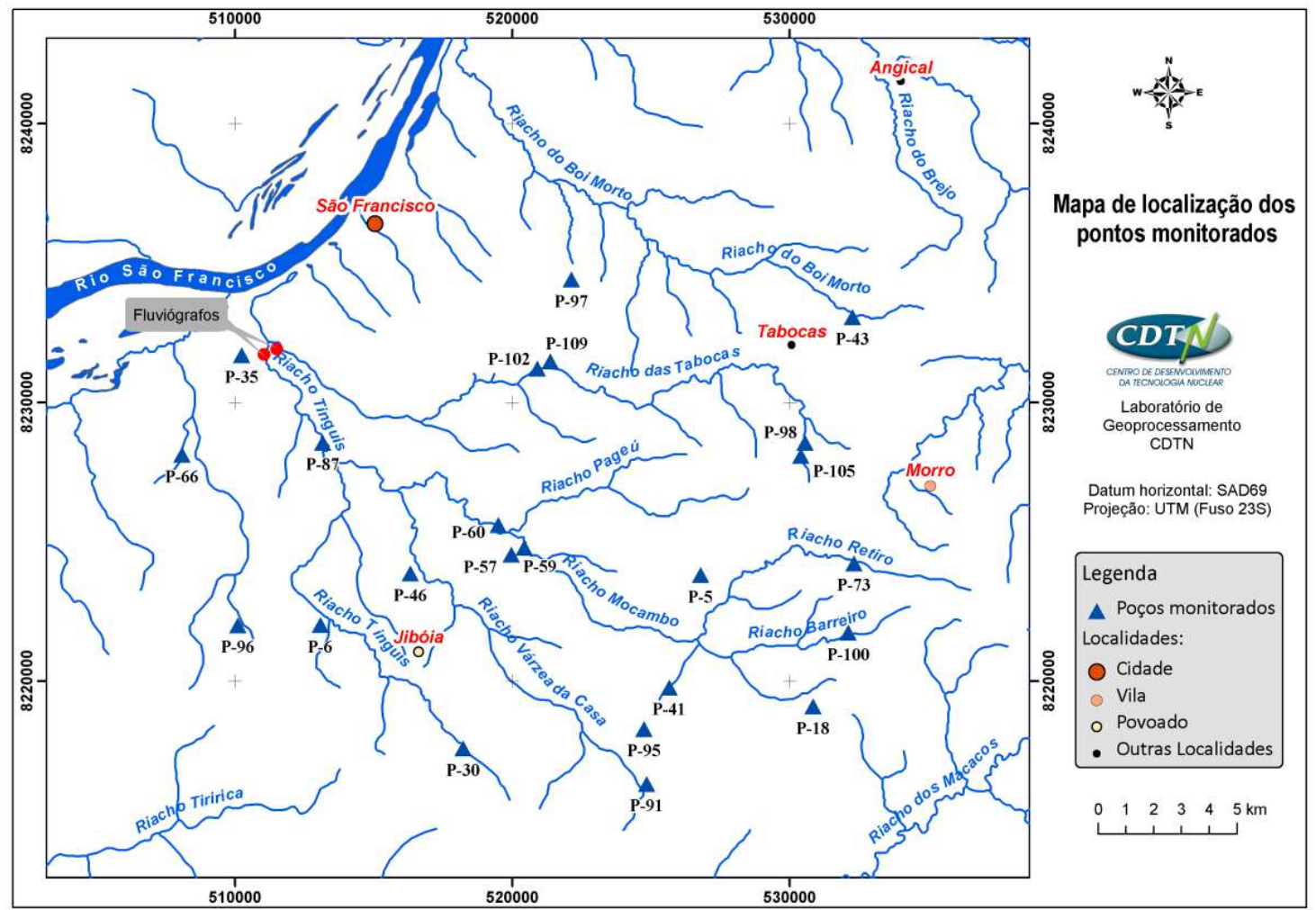

Figura 2 - Localização dos pontos de medida de vazão nos córregos (círculos vermelhos) e poços com medidas de nível piezométrico (triângulos azuis).

Figure 2 - Location of the flow estimation points in the creeks (red circles) and wells with piezometric levels measurements (blue triangles). 
O clima da área é classificado como tropical semi-úmido e quente (PATRUS et al., 2001), com temperatura média de $240 \mathrm{C}^{\circ}$ e índice pluviométrico de $1.053 \mathrm{~mm}$ (médias entre 1938 e 1999), com estação úmida entre novembro e março, seguida de um longo período seco e quente (Classe Aw - Equatorial Desert).

No município de São Francisco, estima-se que $70 \%$ da população rural depende da água subterrânea, devido a baixa disponibilidade hídrica superficial perene e aos custos inferiores de implantação e operação de sistemas com poços tubulares (OLIVEIRA et al., 2007).

No contexto regional, a área está inserida no compartimento central da bacia do São Francisco, constituída de coberturas neoproterozóicas pouco deformadas da porção centro-sul do Cráton do São Francisco.

As principais unidades de preenchimento da bacia do São Francisco são os Supergrupos Espinhaço (Paleo/Mesoproterozóico) e São Francisco (Neoproterozóico), além dos Grupos Santa Fé (permo-carbonífero), Areado, Mata da Corda e Urucuia, todos cretáceos (PINTO e MARTINSNETO, 2001).

Segundo Dardenne (1978), o Grupo Bambuí, pertencente ao Super Grupo São Francisco, é a principal unidade neoproterozóica de cobertura do cráton, compreendendo uma mega-sequência pelítica e carbonática (Subgrupo Paraopeba) recoberta por sedimentos predominantemente siliciclásticos (Fm. Três Marias). Constitui espessa sequência de rochas sedimentares e metassedimentares de baixo grau metamórfico que cobre amplas áreas nos estados de Minas Gerais, Goiás e Bahia.
Formalmente, o Grupo Bambuí é constituído pelas Formações Sete Lagoas (calcários e dolomitos com intercalações localizadas de pelitos), Serra de Santa Helena (folhelhos, siltitos, margas e lentes esparsas de calcário), Lagoa do Jacaré (calcários pretos, com intercalações de siltitos), Serra da Saudade (siltitos e folhelhos) e Três Marias (siltitos, arcósios e arenitos arcosianos) (Departamento Nacional de Produção Mineral, 1982).

Segundo a mesma referência, com exceção da Formação Três Marias, as demais formações, estão reunidas sob a denominação de Subgrupo Paraopeba. As rochas do Grupo Bambuí tem idade neoproterozóica e foram mapeadas por Freire e Castro (2003), na escala 1:60.000 e em detalhe, 1:25.000, em duas áreas chaves no interior desta bacia. Os autores descrevem uma sequência com constantes intercalações de rochas pelíticas e calcários sub-horizontais de espessuras variáveis (centimétricas, métricas a dezenas de metros). No topo, ocorrem os arenitos cretáceos intemperizados do Grupo Urucuia, com espessuras de 20 a $30 \mathrm{~m}$. Sedimentos predominantemente arenosos formam as coberturas eluvio-coluvionares e os aluviões junto ao rio São Francisco.

Devido a tal diversidade litológica e em função do objeto do trabalho, com exceção dos arenitos do Grupo Urucuia, a ausência de estudos que comprovadamente correlacionem as unidades mapeadas à estratigrafia formal do Grupo Bambuí, optou-se pela identificação das unidades litológicas, tanto quanto possível, de acordo com a predominância dos termos pelítico ou carbonático (Figura 3). 


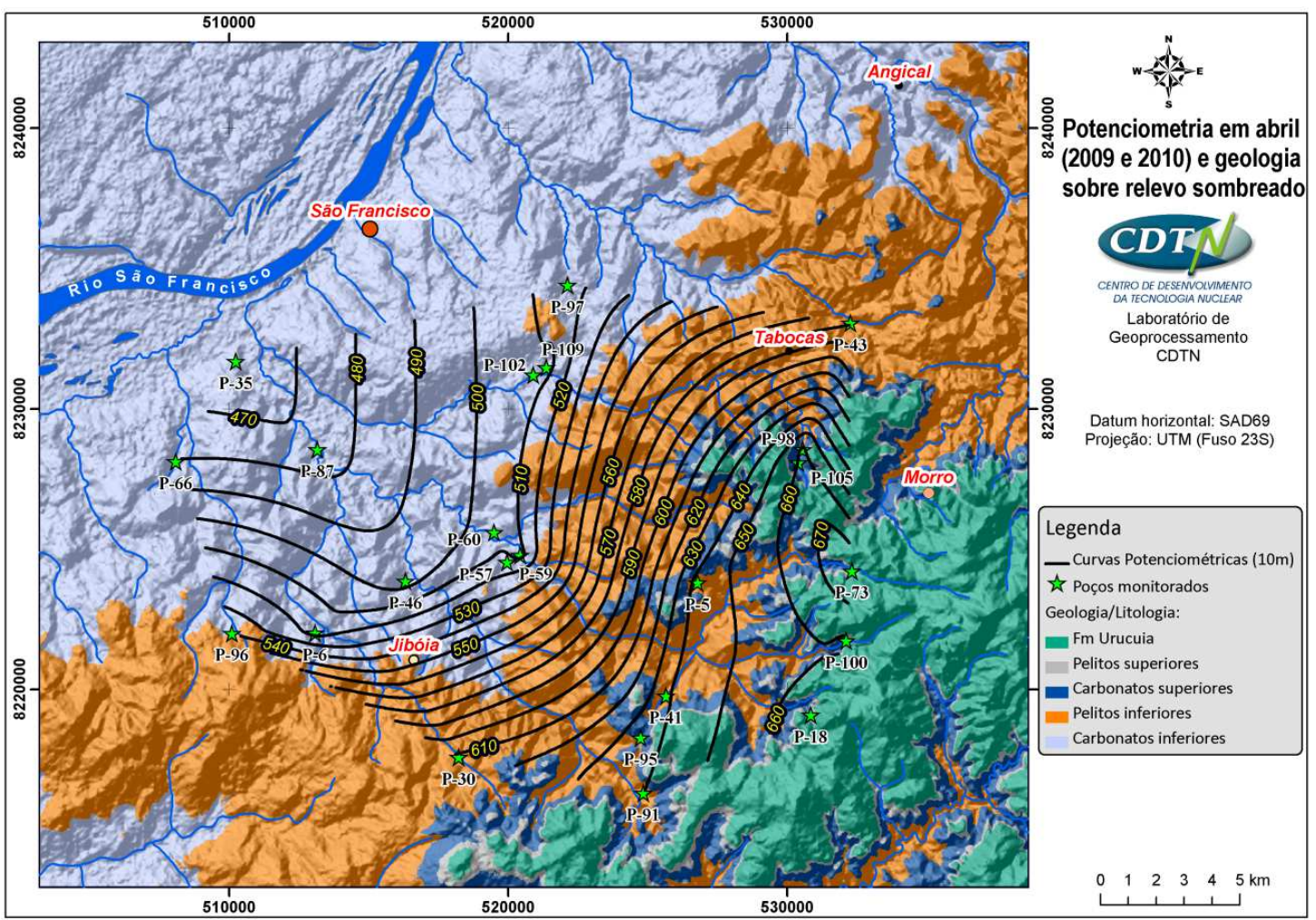

Figura 3 - Mapa geológico simplificado e potenciometria da bacia do riacho Mocambo do riacho Mocambo em abril (2009 e 2010).

Figure 3 - Simplified geologic map and potenciometry of the Mocambo creek watershed in April (2009 and 2010).

Com base no mapeamento geológico e em dados de perfis geológicos de poços tubulares per furados pela Companhia de Saneamento de Minas Gerais (COPASA/MG), identificaram-se quatro unidades hidroestratigráficas, da base para o topo: i) Calcário inferior, abaixo da cota $550 \mathrm{~m}$, formando um aquífero cárstico-fissural inferior; ii) Pelito intercalado com calcário, com espessuras das camadas pelíticas e carbonáticas variando entre $10 \mathrm{e}$ 30 metros, funcionando como aquitardo; iii) Calcário superior, com 40 metros de espessura, ocorrendo acima da cota $640 \mathrm{~m}$, constituindo o aquífero cárstico-fissural superior, e, iv) Arenitos do Grupo Urucuia com 20 a $30 \mathrm{~m}$ de espessura.

Em estudo geológico abrangendo a porção do município correspondente à margem direita do rio São Francisco, Freire e Castro (2003) mediram as fraturas sub-verticais nos calcários e dutos gerados pela dissolução cárstica. Embora os máximos das fraturas e dutos não apresentem uma concordância exata, verifica-se uma associação entre o grupo de direções $\mathrm{N} 30^{\circ}-80^{\circ} \mathrm{W}$ e $\mathrm{N} 10^{\circ}-40^{\circ} \mathrm{E}$ quando comparadas às direções médias das fraturas
$\left(\mathrm{N} 55^{\circ} \mathrm{W}\right.$ e $\left.\mathrm{N} 30^{\circ} \mathrm{E}\right)$ e dos dutos $\left(\mathrm{N} 60^{\circ} \mathrm{W}\right.$ e $\left.\mathrm{N} 25^{\circ} \mathrm{E}\right)$. Salienta-se uma direção marcante de carstificação em $\mathrm{N} 80^{\circ}-90^{\circ} \mathrm{W}$. De acordo com Velásquez et al. (2003) tal direção é concordante com a orientação de fraturas mais abertas dentre todas as demais, sendo de difícil medição em campo por conta da irregularidade da superfície do calcário. Porém, nos metapelitos é a direção de fratura mais frequente. Os autores chamam ainda atenção para a presença constante de fraturas sub-horizontais alargadas pela dissolução cárstica na área desse estudo.

A recarga dos aquíferos cárstico-fissurais na região pode ocorrer de quatro diferentes formas: (a) através dos arenitos do Grupo Urucuia, localizados sobre o Grupo Bambuí, a sudeste da cidade de São Francisco; (b) indiretamente por drenagem vertical através das unidades pelíticas; (c) diretamente nos sedimentos de cobertura e (d) localmente através da infiltração direta em fraturas abertas e dutos cársticos.

As direções e gradientes de fluxo normalmente são complexos em sistemas anisotrópicos 
como aquíferos fissurais e cársticos, e são determinados pelas descontinuidades. No caso em estudo, as componentes horizontais do fluxo nas descontinuidades subverticais e horizontais são predominantes nos locais em que as unidades cársticasfissurais estão presentes e as componentes verticais se tornam ativas na presença de unidades pelíticas. O fluxo do sistema regional ocorre segundo as direções NW no sentido do rio São Francisco, localizado a noroeste da área, correspondendo ao nível regional de base, como será visto adiante por meio do mapa potenciométrico. A partir das medidas de fraturas e dutos acima descritos, possível inferir pelo menos três direções médias potenciais para fluxo $\left(\mathrm{N} 55^{\circ}-60^{\circ} \mathrm{W}, \mathrm{N} 70^{\circ}-90^{\circ} \mathrm{W}\right.$ e $\left.\mathrm{N} 25^{\circ}-30^{\circ} \mathrm{E}\right)$.

Devido à elevada heterogeneidade litológica e topográfica da área estudada, pode-se afirmar que o sistema cárstico-fissural aí encontrado não se enquadra formalmente em apenas um modelo específico dentre os sete propostos por White (2012), senão a alguns deles nas diferentes condições físicas apresentadas. As constantes intercalações subméticas a métricas de metapelitos entre as camadas de calcário sub-horizontais promovem a dissolução e formação de dutos, sumidouros e cavernas de pequeno porte, muitas das quais apresentando preenchimento detrítico posterior, expostos acima do nível de base regional, representado pelo rio São Francisco.

Essa configuração intercalada das litologias promove ainda a compartimentação horizontal dos aquíferos carbonáticos favorecendo, de acordo com a classificação de White (2012), a formação de aquíferos de fluxo livre suspensos abertos (calcários acima do nível do terreno) ou fechados (calcários sotopostos a coberturas detríticas ou metapelitos). No primeiro caso, a recarga direta da chuva e enxurradas é favorecida pelas exposições das fraturas dissolvidas e sumidouros em vários níveis topográficos de tal maneira que mesmo os compartimentos aquíferos topograficamente inferiores podem ser alimentados dessa forma. No segundo caso, a recarga é maior ou menor dependendo da cobertura, e mais limitada entre esses compartimentos quando separados pelos metapelitos.

De uma forma geral, podem-se considerar os fluxos do sistema aquífero como do tipo livre, porém, verifica-se ainda a presença localizada de artesianismo (sob condições jorrantes ou não), assemelhando ao fluxo confinado do tipo sanduíche de White (2012), a exemplo da localidade de Tabocal de Baixo onde está locado um poço jorrante. Com base em observações de campo o calcário nesse local está coberto por uma camada de metapelito aflorante. Abaixo do nível de base, as rochas calcárias saturadas persistem até uma profundidade mínima de $135 \mathrm{~m}$, observada a partir de dados de poços. É possível que o aquífero seja cofinado nessa porção, entretanto a ausência de dados litológicos dos poços não permite tal afirmação até o momento.

\section{ASPECTOS HIDROLÓGICOS E HIDROGE- OLÓGICOS}

As médias pluviométricas mensais entre os anos de 2000 e 2005 medidos na Estação da Agência Nacional das Águas (ANA) número 1544020 de São Francisco - MG (ANA, 2010), bem como as temperaturas médias mensais entre 1961 a 1978 , foram utilizadas para a elaboração do balanço hídrico mensal pelo método Thornthwaite e Mather (1955). O resultado do balanço hídrico demonstrou a importância da evapotranspiração na região (782,2 $\mathrm{mm} /$ ano para uma precipitação média no período de 1016,6 mm/ano), gerando um excedente hídrico anual de $234,4 \mathrm{~mm} / \mathrm{ano}$. Esse valor, que compreende, basicamente, dois outros componentes do balanço hídrico, a recarga e o escoamento superficial, foi utilizado como base para a definição dos valores de recarga na elaboração do modelo de fluxo.

As vazões dos riachos Mocambo e Tabocal, no final do período de chuva (março/abril), foram estimadas a partir de um monitoramento contínuo da lâmina d'água realizado em pontos próximos ao local onde os dois riachos se reúnem (pontos marcados como "Fluviógrafos" na Figura 2). Para a estimativa das vazões, foi levantada a geometria da seção de cada riacho no trecho monitorado e montada uma planilha com valores incrementais de altura, calculando-se, para cada incremento, a área e o perímetro molhado. Utilizando valores de rugosidade de literatura e declividades medidas em cada uma das seções, foi realizada 
uma regressão linear com os dados para obter as equações de vazão versus altura. As vazões dos riachos Mocambo e Tabocal no período foram estimadas em 1000 e $2000 \mathrm{~m}^{3} / \mathrm{h}$, respectivamente.

Os níveis piezométricos de 23 poços tubulares da região foram registrados em abril de 2009 e abril de 2010 (Figura 2), datas referentes ao final do período chuvoso (Tabela 1). Para essa medida, os poços tubulares em operação foram desligados por 24 horas ou até que o nível se estabilizasse (nível estático). Os dados digitais de elevação (MDE) na região da bacia do córrego Mocambo foram obtidos no site do projeto TOPODATA (INSTITUTO NACIONAL DE PERQUISAS ESPACIAIS, 2011). Esses dados foram interpolados previamente pelo Instituto Nacional de Pesquisas Espaciais (INPE) para uma grade de 30x30m a partir dos originais SRTM (90x90m).

Tabela 1 - Dados de altimetria e cotas dos níveis piezométricos estáticos para os poços monitorados em abril/2009 e abril/2010.

Table 1 - Altimetry and static piezometric head data for the monitored wells in April/2009 and April/2010.

\begin{tabular}{|c|c|c|c|c|}
\hline Poço & Altimetria (m) & $\begin{array}{c}\text { Cota NE } \\
\text { Abril/2009 (m) }\end{array}$ & $\begin{array}{c}\text { Cota NE } \\
\text { Abril/2010 (m) }\end{array}$ & $\begin{array}{c}\text { Cota NE média } \\
\text { em Abril (m) }\end{array}$ \\
\hline P-5 & 648 & 645 & 644 & 644 \\
\hline P-6 & 518 & 517 & 517 & 517 \\
\hline P-18 & 678 & 666 & 668 & 667 \\
\hline $\mathrm{P}-30$ & 613 & & 612 & 612 \\
\hline $\mathrm{P}-35$ & 477 & 460 & & 460 \\
\hline $\mathrm{P}-41$ & 642 & 639 & & 639 \\
\hline $\mathrm{P}-43$ & 587 & 578 & 580 & 579 \\
\hline $\mathrm{P}-46$ & 497 & 496 & & 496 \\
\hline P-57 & 553 & 515 & & 515 \\
\hline P-59 & 520 & 506 & & 506 \\
\hline P-60 & 514 & 503 & 503 & 503 \\
\hline P-66 & 506 & 480 & 481 & 481 \\
\hline P-73 & 484 & & 680 & 680 \\
\hline $\mathrm{P}-87$ & 684 & 474 & 474 & 474 \\
\hline P-91 & 476 & 640 & 640 & 640 \\
\hline P-95 & 644 & 635 & & 635 \\
\hline P-96 & 658 & 539 & & 539 \\
\hline P-97 & 552 & 516 & & 516 \\
\hline P-98 & 525 & 662 & & 662 \\
\hline $\mathrm{P}-100$ & 669 & 658 & 659 & 659 \\
\hline P-102 & 517 & 509 & & 509 \\
\hline $\mathrm{P}-105$ & 665 & & 660 & 660 \\
\hline P-109 & 517 & & 506 & 506 \\
\hline
\end{tabular}


O mapa potenciométrico dos aquíferos na bacia do riacho Mocambo (Figura 3) foi obtido por interpolação a partir dos dados de nível d'água medidos nos poços tubulares em abril de 2009 e abril de 2010. Para os poços com dados disponíveis em ambos os anos avaliados, foi assumido o nível piezométrico médio para a elaboração do mapa (última coluna da Tabela 1). Por representar a potenciometria em aquíferos cárstico-fissurais, que tem a característica de armazenar água somente em zonas de fraturamento ou em condutos, tal mapa deve ser visto com reservas, já que não é possível se pode prever a continuidade do aquífero, mesmo que o mapa potenciométrico indique. $\mathrm{O}$ mapa deve ser visto apenas como um indicativo dos gradientes e direções de fluxo predominantes, que estão de acordo com os sistemas de fraturas observados.

É possível verificar que as cargas hidráulicas acompanham a topografia da bacia, apresentando linhas de fluxo convergentes em direção ao rio São Francisco. Duas áreas de maior condutividade hidráulica são identificadas, respectivamente nas áreas mais altas e mais baixas do terreno. Entre elas, há uma zona de menor condutividade hidráulica, mostrada pela queda mais acentuada na carga hidráulica. Essas características acompanham, de forma geral, a geologia da região, em que os dois principais aquíferos carbonáticos são intercalados com lentes pelíticas, como se pode observar na Figura 3. Na região dos pelitos inferiores, os maiores gradientes hidráulicos podem ser explicados pela predominância de componentes de fluxo verticais, enquanto que na região mais próxima ao rio São Francisco, a predominância de componentes de fluxo horizontais, típicos de unidades cársticasfissurais explicam os menores gradientes hidráuli$\cos$.

\section{MODELO CONCEITUAL DO FLUXO SUB- TERRÂNEO}

Com base na compilação dos dados coletados, foi assumido um modelo conceitual de fluxo subterrâneo para ser a base da elaboração do modelo matemático de fluxo. A principal hipótese assumida é que a abordagem de meio poroso equivalente é válida para a descrição do fluxo subterrâneo na área simulada. Essa hipótese se baseou nas análises em Marques et al. (2011a; 2011b), onde os níveis piezométricos dos poços foram analisados com funções de autocorrelação (ACF) e correlação cruzada. O correlograma de uma ACF permite a avaliação do efeito memória de um sistema (neste caso, o aquífero) e, do ponto de vista hidrogeológico, informa sobre o grau de desenvolvimento do carste. Segundo Panagopoulos e Lambrakis (2006) e Ferrari e Karmann (2008), carstes ativos e bem desenvolvidos apresentam efeito de memória fraco, o que se reflete em correlogramas com decaimento acelerado e tempos de descorrelação curtos. Em Marques et al. (2011a, b), os resultados apontam para tempos de descorrelação mais curtos em vários trechos da bacia (alto, médio e baixo), excetuando-se um poço mais distante. As funções de correlação cruzada (chuva versus variação no nível dos poços) apresentaram maiores coeficientes para lags entre 4 e 6 dias, indicativo de baixa inércia do sistema aquífero e maior desenvolvimento do carste, corroborando os resultados da ACF.

É importante ressaltar que existe uma limitação inerente a estes métodos para explicar todo o comportamento do aquífero, como lembram Ferrari e Karmann (2008), havendo a necessidade da complementação com outras análises, por exemplo, com a utilização de traçadores. Entretanto, até o presente momento, os resultados apontam para um possível carste com a presença de redes de fissuras e dutos desenvolvidos o suficiente para produzir uma resposta hidráulica que possa ser simulada com os métodos de modelagem de fluxo aqui apresentados.

O modelo conceitual assumido para a área é baseado nos seguintes componentes principais: O fluxo nos aquíferos é essencialmente horizontal, como consequência da presença de camadas geológicas sub-horizontais. São consideradas três camadas: aquífero carbonífero superior, aquitardo composto de camadas finas de carbonatos e pelitos e aquífero carbonífero inferior;

$\checkmark \quad$ Os limites do fluxo subterrâneo na bacia foram baseados em limites físicos e na análise da potenciometria de abril/2009 e abril/2010. Foram assumidos os seguintes limites: a noroeste, o rio São Francisco; a oeste e norte, foram utilizadas as 
linhas de fluxo que acompanham os riachos Novo Horizonte e Boi Morto, respectivamente; na faixa compreendida entre a direção sul e leste, foi utilizado o divisor da bacia hidrográfica como fluxo nulo; a nordeste, entre o riacho Boi Morto e o divisor de águas da bacia, foi utilizada, como limite, uma nascente desse riacho;

O principal mecanismo de entrada de água é a recarga natural, quantificada como uma fração do excedente hídrico obtido pelo balanço hídrico da bacia, principalmente na área mais elevada, coberta pelo aquífero carbonático superior e os arenitos Urucuia. As coberturas dispostas direta- mente sobre o aquífero carbonático também devem constituir uma zona de recarga. Devido à topogra fia acidentada e à menor permeabilidade, não foi considerada recarga na área do aquitardo;

As descargas da bacia estudada foram consideradas como sendo através do rio São Francisco, ao longo dos pequenos riachos que drenam o aquífero quando em seu nível mais elevado (após o período de chuvas) e na área da cabeceira do riacho Tabocal, formando uma nascente do riacho Boi Morto.

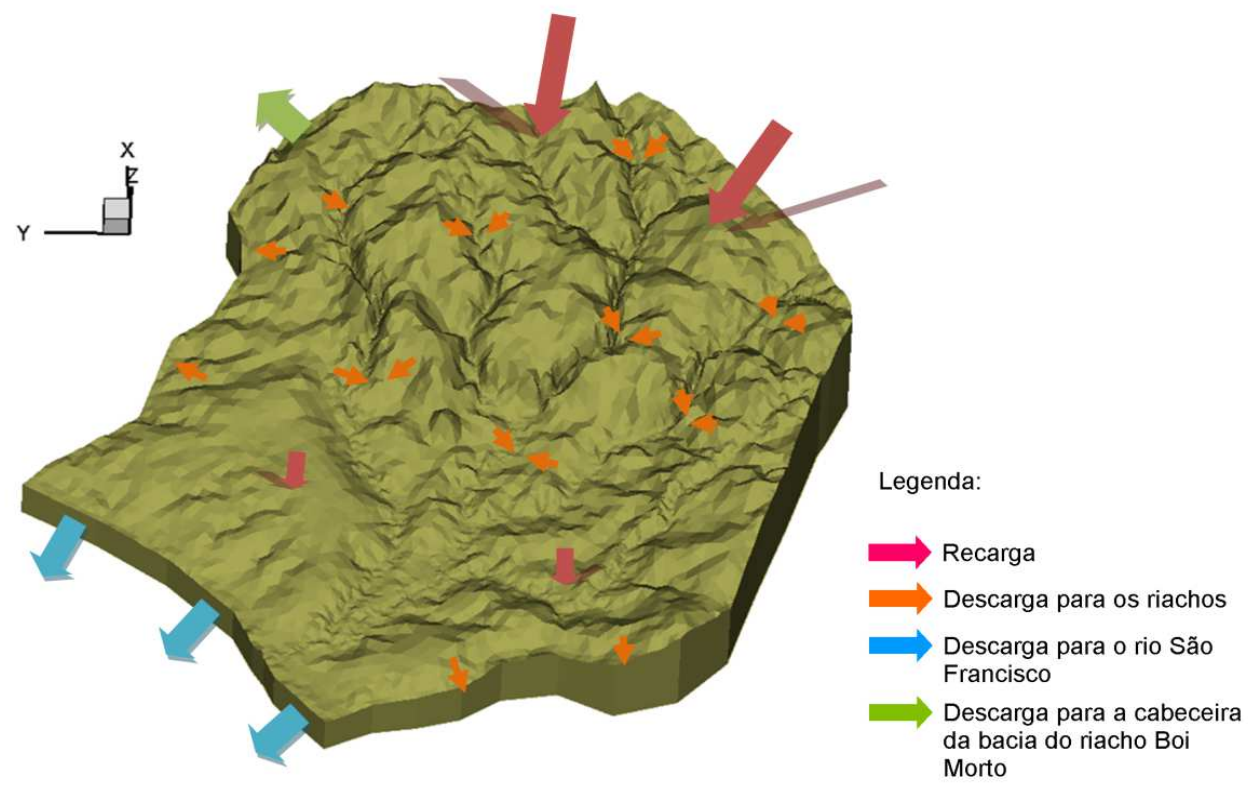

Figura 4 - Representação gráfica do modelo conceitual do fluxo subterrâneo. Figure 4 - Graphic representation of the groundwater conceptual model.

\section{MODELAGEM NUMÉRICA DO FLUXO DAS ÁGUAS SUBTERRÂNEAS}

O programa utilizado, HydroGeoSphere A Three-dimensional Numerical Model Describing Fully-integrated Subsurface and Surface Flow and Solute Transport (TERRIEN et al., 2009), combina módulos acoplados de fluxo e transporte subterrâneo com fluxo superficial e de qualidade da água. As equações diferenciais são resolvidas pelo método dos elementos dos volumes finitos, com linearização dada pelo método de Newton-Raphson. O programa computacional utilizado para a simulação, o HydroGeoSphere, possui como principal vantagem, face a outros pacotes utilizados para a simulação numérica de fluxo das águas subterrâ- neas, a capacidade de simular integralmente todos os aspectos do ciclo hidrológico, permitindo que a precipitação se divida, baseando-se em princípios físicos, em seus fluxos principais: escoamento superficial, evaporação, transpiração, recarga subterrânea e descarga subterrânea em corpos de água superficiais. Além disso, os métodos numéricos empregados são rápidos, robustos e estáveis. $\mathrm{O}$ modelo também é muito bem aplicado na simulação de meios fraturados através de diferentes abordagens (meio poroso equivalente, porosidade dupla, rede de fraturas discretas) (BRUNNER e SIMMONS, 2012). Segundo os autores, a principal 
limitação do programa reside nas deficiências da documentação, cujas atualizações não acompanham àquelas realizadas no programa, e a necessidade do uso de pós-processadores comerciais para a visualização dos resultados.

Para a presente modelagem foram utilizados apenas os módulos referentes ao fluxo saturado e, como o programa HydroGeoSphere não calcula diretamente a solução em regime permanente, esta foi obtida simulando a evolução temporal com condições constantes no tempo, até que não houvesse mais mudança significativa nos resultados entre dois intervalos de tempo consecutivos.

\section{Limites do domínio e desenho da malha}

Os limites assumidos para o domínio foram definidos com base no mapa potenciométrico elaborado (Figura 3), sendo que, a estes limites, foram atribuídas as condições de contorno descritas a seguir. De sul a leste, foram utilizados os limites da bacia hidrográfica. A nordeste o riacho Boi Morto foi utilizado, aproveitando as linhas de fluxo mostradas no mapa potenciométrico, que indica fluxo aproximadamente paralelo a esse riacho. O mesmo conceito foi aplicado ao limite oeste, com o riacho Novo Horizonte. Novamente, nesse caso, o mapa potenciométrico indica linhas de fluxo paralelas ao riacho. No limite noroeste, foi utilizado o trecho do rio São Francisco que intercepta a área.

Uma malha com elementos triangulares foi projetada para a área, com comprimento de lado máximo de $500 \mathrm{~m}$. Ao longo dos riachos, e em torno do contorno, foi introduzido um refinamento com elementos triangulares de máximo de lado de $100 \mathrm{~m}$. A malha bidimensional foi gerada automaticamente através do software Grid Builder (McLAREN, 2009), através do qual toda a parte geométrica de entrada de dados é realizada.

A malha tridimensional, construída através de comandos de geração de internos ao HydroGeoSphere, baseando-se na malha bidimensional preparada no Grid Builder, contém três camadas (Figura 5), assim descritas da base para o topo: $1^{\mathrm{a}}$. camada com base na cota $350 \mathrm{~m}$ e topo a $380 \mathrm{~m}$ (subdividida em duas subcamadas); $2^{\mathrm{a}}$. camada com topo na cota $400 \mathrm{~m} ; 3^{\mathrm{a}}$. camada com topo dado pela topografia do terreno (10 subcamadas com espessuras variáveis). As subcamadas no modelo HydroGeoSphere permitem melhorar a discretização de cada unidade litológica.

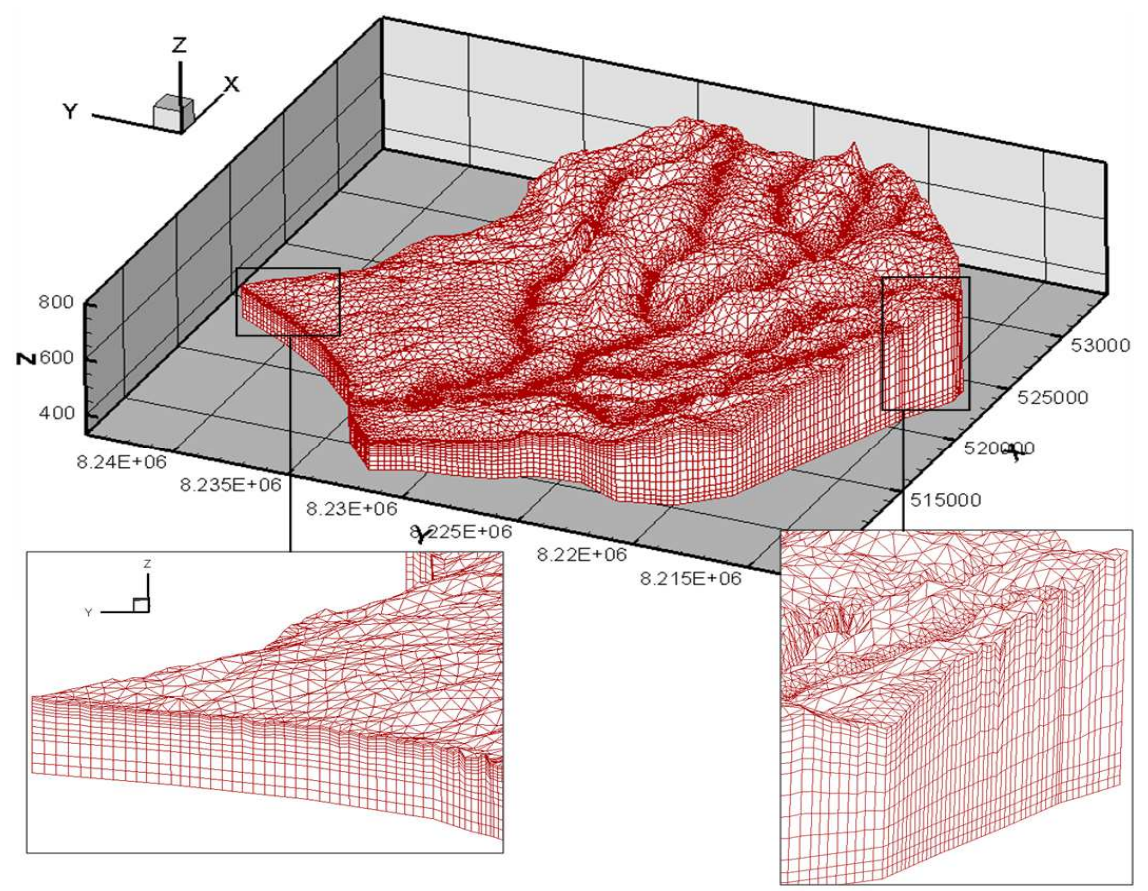

Figura 5 - Malha tridimensional projetada para o domínio simulado.

Figure 5 - Design of the three-dimensional grid for the simulated domain. 


\section{Condições de contorno e iniciais}

A recarga na parte alta do terreno, correspondente à área com carbonatos e arenitos, foi considerada a principal fonte de entrada de água e a taxa de recarga foi considerada como parâmetro de calibração. Na parte baixa do terreno, onde os carbonatos estão novamente expostos, foi aplicada uma taxa de recarga mais baixa, de $1 \%$ do excedente hídrico. Para isso, os elementos correspondentes às duas áreas de recarga foram selecionados utilizando o programa Grid Builder e os valores de taxa de recarga constante foram atribuídos à camada mais superficial do modelo.

A descarga do aquífero inferior para o rio São Francisco foi simulada considerando-se a carga especificada de $440 \mathrm{~m}$, aplicada nas 13 subcamadas do domínio. Os nódulos correspondentes aos pequenos riachos intermitentes foram selecionados no Grid Builder e a condição de contorno tipo Dreno foi especificada para a camada mais superficial do domínio. Por se tratar de riachos pequenos, a carga hidráulica associada à condição de contorno foi tomada como sendo igual à elevação do terreno. O parâmetro condutância foi mantido alto o suficiente para que a carga no domínio seja igual à carga associada aos drenos (1000 $\left.\mathrm{m}^{2} / \mathrm{h}\right)$.

No início do processo de calibração, a descarga para a cabeceira da bacia do riacho Boi Morto não foi considerada. Como forma de se incluir essa descarga na calibração final, foi aplicada a condição de contorno Dreno com cargas hidráulicas baseadas na potenciometria dos nódulos ao longo do limite nordeste do domínio, que acompa- nha a nascente do riacho Boi Morto. A condutância foi mantida elevada a fim de que as cargas nos nódulos sejam iguais às cargas nos drenos.

Os elementos pertencentes a cada unidade hidrogeológica foram selecionados no Grid Builder e cada propriedade aplicada diretamente através de comandos internos do HydroGeoSphere durante a montagem do arquivo de entrada de dados. As propriedades referentes a cada unidade foram distribuídas para as diferentes camadas tendo, como base, as elevações que as delimitam: carbonato superior acima da cota $640 \mathrm{~m}$, aquitardo entre as cotas 640 e $550 \mathrm{~m}$ e carbonato inferior abaixo da cota $550 \mathrm{~m}$. A norte do riacho Tabocal, a falha geológica identificada e a consequente alteração da geologia local, foi considerada no modelo. Nessa área, a espessura das camadas de carbonato superior e de aquitardo são maiores, não havendo exposição do carbonato inferior. Os valores de condutividade hidráulica para cada um dos materiais foram escolhidos por meio da calibração do modelo de fluxo em regime permanente, embora se tenha procurado manter os valores dentro de faixas consideradas aceitáveis pela literatura. A distribuição inicial dos tipos litológicos (ou materiais, na nomenclatura adotada pelo modelo) é mostrada na Figura 6, em que se podem observar oito zonas de parâmetros hidrodinâmicos, embora se tenha apenas três tipos litológicos: aquífero superior, nas áreas mais elevadas da bacia do Mocambo e do Boi Morto (zonas 5, 6 e 8); aquitardo, na zona de elevação intermediária na bacia do Mocambo e nas camadas mais superficiais do restante da bacia do Boi Morto (zonas 4 e 7); aquífero inferior, nas camadas inferiores de toda a área (zonas 1, 2 e 3). 


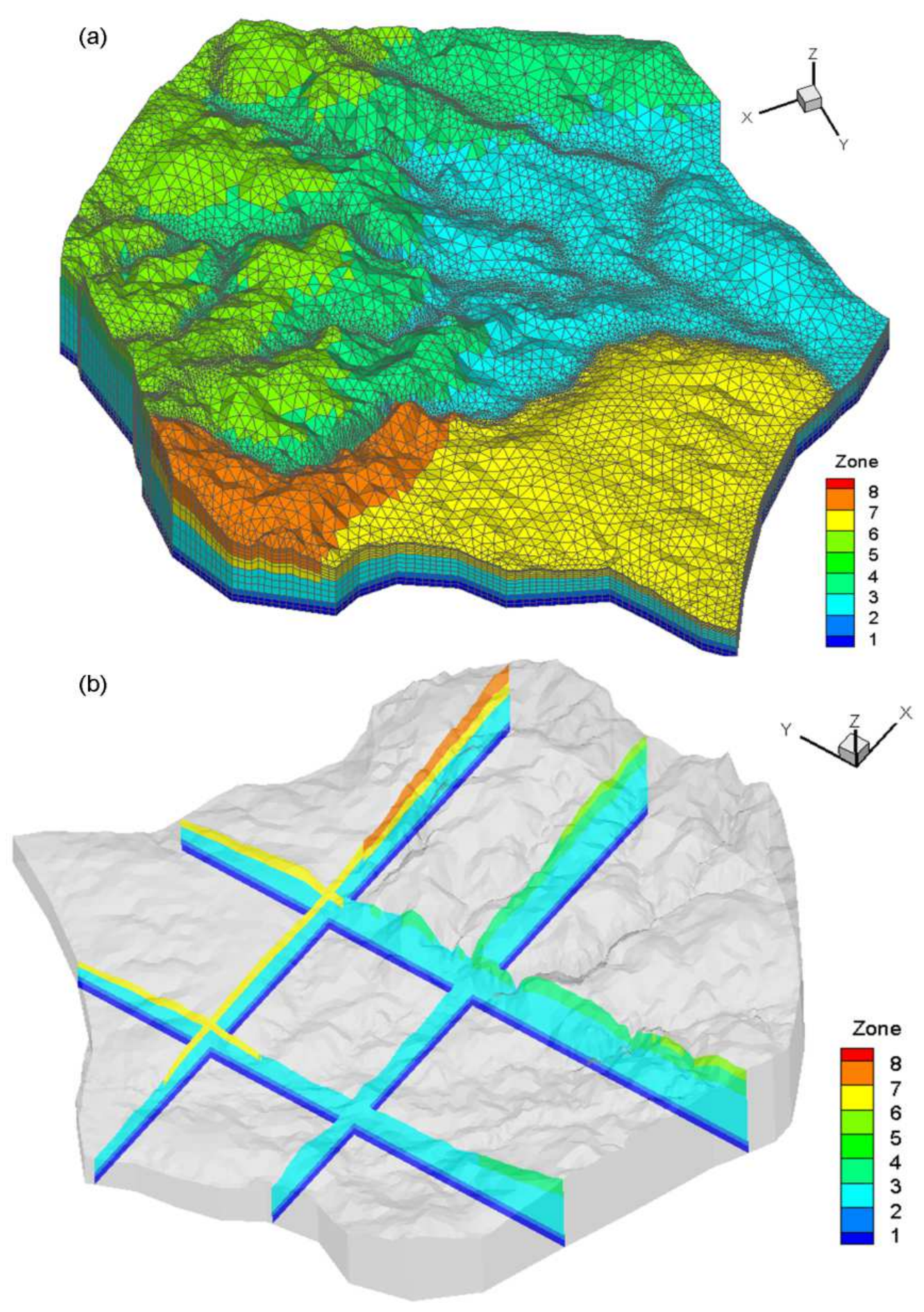

Figura 6 - Zonificação inicial do modelo em regime permanente: (a) visão geral; (b) seções verticais. Figure 6 - Initial zone arrangement for steady-state model: (a) overall view; (b) vertical profiles. 
A condição inicial da modelagem foi estabelecida com sendo o aquífero totalmente saturado, com as cargas hidráulicas iguais à elevação do terreno em cada ponto. Entretanto, numa calibração em regime permanente, a condição inicial não afeta o resultado final, apenas o tempo necessário para atingir o regime estacionário e a taxa de convergência da solução numérica.

\section{Processo de calibração}

$\mathrm{Na}$ avaliação da calibração, foram utilizados os dados potenciométricos combinados, obtidos em abril/09 e abril/10, sendo que, para os poços com dados disponíveis nos dois períodos de medida, foi assumida a carga hidráulica média. A elevação dos pontos de observação verticais em cada poço de monitoramento foi definida como sendo $2 \mathrm{~m}$ abaixo da elevação da superfície freática, caracterizando a medida superficial de potenciometria realizada. Além dos valores de carga hidráulica, para verificação da calibração foram também utilizados os valores de vazão nas seções de monitoramento dos riachos Mocambo e Tabocal e a estimativa do aporte subterrâneo da bacia para o rio São Francisco.

Numa etapa preliminar da calibração foram ajustados os parâmetros de condutividade hidráulica das diferentes camadas que compõem o modelo e as taxas de recarga aplicadas. Em um segundo momento, um detalhamento espacial dos parâmetros foi realizado visando melhorar o ajuste do modelo em pontos específicos.

O processo de calibração foi iniciado pela fixação de um valor base para a recarga aplicada nos aquíferos carbonáticos superior e inferior, através de uma análise de sensibilidade. Para esse processo, o valor de condutividade hidráulica nos carbonatos foi fixado como sendo igual a um valor representativo de areia grossa $\left(1.10^{-2} \mathrm{~m} / \mathrm{h}\right)$. Para o aquitardo, esse parâmetro foi fixado, arbitrariamente, como sendo 1000 vezes menor do que o valor para a areia. $\mathrm{O}$ valor inicial para a recarga escolhido por esse processo foi de $30 \%$ do excedente hídrico aplicado no aquífero superior e $1 \%$ aplicado no aquífero inferior. A partir desse ponto, os valores de condutividade hidráulica foram ajustados progressivamente buscando reproduzir o formato das curvas potenciométricas e reduzir os parâmetros estatísticos de ajuste do modelo. Após esgotar as alternativas que possam reduzir os erros apenas alterando os valores gerais dos parâmetros, a estratégia de calibração passou a abordar as heterogeneidades em pontos específicos do aquífero, alterando os valores de condutividade hidráulica localmente.

Entre as ações realizadas, citam-se: introdução de drenos para considerar a saída de água na cabeceira do riacho Tabocal em direção à cabeceira do riacho Boi Morto (já prevista no modelo conceitual); aumento da área de recarga próximo às cabeceiras dos riachos Várzea de Casa e Tinguis; introdução da condição de contorno de fluxo especificado em torno do poço P-109, aplicado somente na camada mais elevada como forma de testar uma suspeita de superexplotação local; ajustes dos valores de condutividade hidráulica em locais específicos, de modo a reproduzir valores anômalos observados de cargas hidráulicas, possivelmente resultantes de zonas de fraturamento diferenciado ou pela presença de dutos cársticos.

\section{RESULTADOS E DISCUSSÃO}

O processo de calibração aplicado na elaboração do modelo numérico de fluxo em regime permanente apresentou resultados satisfatórios com base nos parâmetros de comparação escolhidos. A Tabela 2 apresenta os valores finais dos parâmetros utilizados na calibração para o modelo calibrado. A Tabela 3 apresenta os erros estatísticos da calibração e o balanço hídrico nas condições de contorno para o modelo calibrado. A forma de cálculo dos erros médios da calibração também é mostrada na Tabela 3. Na Figura 7, é apresentado graficamente o ajuste dos resultados de carga hidráulica calculados pelo modelo aos valores observados, sendo que a proximidade dos pontos com a linha vermelha (ajuste ideal) indica um bom grau de ajuste. 
Tabela 2 - Valores finais dos parâmetros de calibração para o modelo permanente.

Table 2 - Final values for the calibration parameters of the steady-state model

\begin{tabular}{c|c}
\hline \hline Parâmetro & Valor \\
\hline $\begin{array}{c}\mathrm{K} \\
\text { (aquífero superior) }\end{array}$ & $6,0.10^{-2} \mathrm{~m} / \mathrm{h}$ \\
\hline $\begin{array}{c}\mathrm{K} \\
\text { (aquitardo) }\end{array}$ & $8,0.10^{-6} \mathrm{~m} / \mathrm{h}$ \\
\hline $\begin{array}{c}\mathrm{K} \\
\text { (aquífero inferior) }\end{array}$ & $1,0.10^{-2} \mathrm{~m} / \mathrm{h}$ \\
\hline $\begin{array}{c}\text { Recarga } \\
\text { (aquífero superior) }\end{array}$ & $9,35.10^{-6} \mathrm{~m} / \mathrm{h}(35 \%$ exc. híd.) \\
\hline $\begin{array}{c}\text { Recarga } \\
\text { (aquífero inferior) }\end{array}$ & $2,67.10^{-7} \mathrm{~m} / \mathrm{h}(1 \%$ exc. híd.) \\
\hline \hline
\end{tabular}

Tabela 3 - Resultados da calibração: estimativa dos erros de calibração e balanço hídrico nas condições de contorno. Table 3 - Calibration results: calibration error estimative and water budget in the boundary conditions.

Erros estatísticos de calibração

\begin{tabular}{|c|c|c|c|c|}
\hline $\begin{array}{l}\text { Erro médio } \\
\frac{\sum_{\mathrm{i}=1}^{\mathrm{N}}\left(\mathrm{h}_{\mathrm{c}}-\mathrm{h}_{\mathrm{m}}\right)_{\mathrm{s}}}{\mathrm{N}}\end{array}$ & $\begin{array}{c}\begin{array}{c}\text { Erro médio } \\
\text { absoluto }\end{array} \\
\frac{\sum_{\mathrm{i}=1}^{\mathrm{N}}\left\|\left(\mathrm{h}_{\mathrm{g}}-\mathrm{h}_{\mathrm{m}}\right)_{\mathrm{i}}\right\|}{\mathrm{N}}\end{array}$ & $\begin{array}{l}\text { Erro médio qua- } \\
\text { drático } \\
\text { (EQM) } \\
\left(\frac{\sum_{i=1}^{N}\left(h_{\mathrm{r}}-h_{\mathrm{m}}\right)_{i}^{2}}{\mathrm{~N}}\right)^{1 / 2}\end{array}$ & $\begin{array}{l}\text { Erro médio quadrá- } \\
\text { tico normalizado } \\
(\%) \\
\frac{\text { EQM.100 }}{\left(h_{\operatorname{Max}}-h_{\operatorname{Sin}}\right)}\end{array}$ & $\begin{array}{l}\text { Erro local } \\
\left(h_{\mathrm{c}}-h_{\mathrm{m}}\right)_{\mathrm{i}}\end{array}$ \\
\hline $0,67 \mathrm{~m}$ & $3,02 \mathrm{~m}$ & $3,33 \mathrm{~m}$ & $1,51 \%$ & $\begin{array}{l}\text { Máximo negativo: } \\
-5,28 \mathrm{~m} \text { (P-66) } \\
\text { Máximo positivo: } \\
\text { 5,21 (P-91) }\end{array}$ \\
\hline
\end{tabular}

Balanço hídrico nas condições de contorno

\begin{tabular}{c|l}
\hline \multicolumn{1}{c|}{ Entrada } & \multicolumn{1}{c}{ Saída } \\
Recarga: $1152 \mathrm{~m}^{3} / \mathrm{h}$ & Carga especificada: $156 \mathrm{~m}^{3} / \mathrm{h}$ \\
& Drenos: $986 \mathrm{~m}^{3} / \mathrm{h}$ \\
& Fluxo especificado: $0,4 \mathrm{~m}^{3} / \mathrm{h}$ \\
& \\
\hline \hline
\end{tabular}

Obs: $\mathrm{h}_{\mathrm{m}}$ carga observada em determinado poço $\mathrm{i} ; \mathrm{h}_{\mathrm{c}}$ : carga calculada pelo modelo em uma posição próxima ao poço i; N: número de poços utilizado na calibração; $\mathrm{h}_{\text {Max }}$ : carga máxima observada; $\mathrm{h}_{\text {Min }}$ : carga mínima observada 


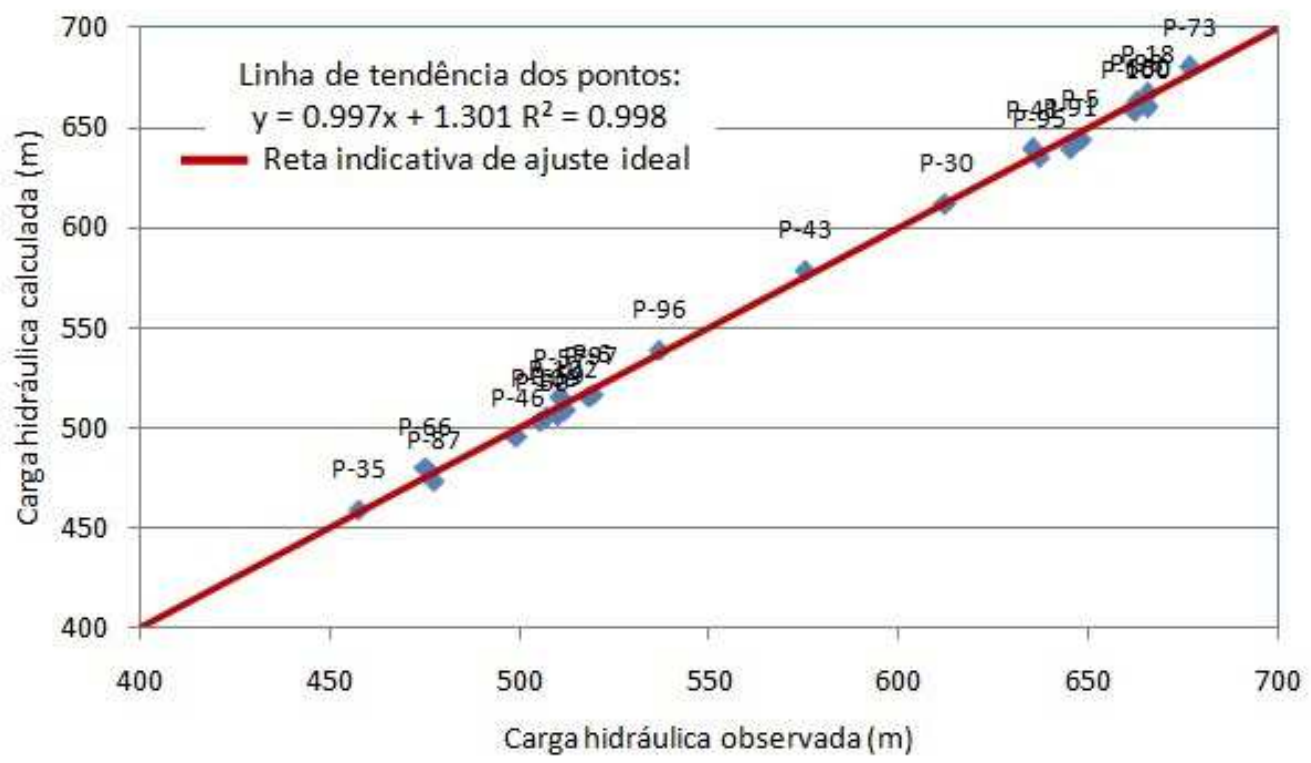

Figura 7 - Ajuste da calibração para o modelo permanente de fluxo.

Figure 7 - Calibration output for the steady-state flow model.

O erro médio quadrático após a calibração do modelo foi de $3,33 \mathrm{~m}(1,5 \%)$, podendo ser considerado satisfatório para o gradiente hidráulico da região simulada. Localmente, o erro máximo foi de $5,2 \mathrm{~m}$. O formato das curvas isopotenciométricas apresentadas na Figura 8 reproduzem de forma satisfatória o mapa potenciométrico elaborado para a área para os dados de abril/2009 e 2010, mostrando linhas de fluxo convergentes em direção ao rio São Francisco.

A entrada de água por recarga no sistema subsuperficial foi estimada em $1152 \mathrm{~m}^{3} / \mathrm{h}$, correspondente às duas áreas de recarga definidas no modelo conceitual: a área de carbonatos superiores, com recarga aplicada de $82 \mathrm{~mm} / \mathrm{ano}$, e dos carbonatos inferiores, com recarga de $2,3 \mathrm{~mm} / \mathrm{ano}$. A descarga através da condição de contorno de carga especificada, equivalente a $155 \mathrm{~m}^{3} / \mathrm{h}$, se relaciona com a contribuição subterrânea da bacia do riacho Mocambo ao fluxo do rio São Francisco. Este valor é pequeno se comparado com a vazão média do rio São Francisco na seção de controle da ANA no município de São Francisco nos meses de março e abril entre 2000 e 2011 (ANA, 2012), em torno de $9.106 \mathrm{~m}^{3} / \mathrm{h}$, como esperado para o porte da bacia.
Comparativamente, a descarga pelos drenos, estimada em $986 \mathrm{~m}^{3} / \mathrm{h}$, é muito mais significativa. Esse valor reflete a descarga dos aquíferos nos riachos ao fim do período de chuva (abril). Apesar dos riachos na região serem, na sua maioria, intermitentes, secando ao longo do período de estiagem, no momento considerado o valor calculado pelo modelo está de acordo com o estimado através de medições. O valor de vazão, estimado em março/2010 para as seções dos riachos Mocambo e Tabocal, totalizou $3000 \mathrm{~m}^{3} / \mathrm{h}$, estando dentro da ordem de grandeza do valor calculado pelo modelo.

Tanto o valor da descarga dos aquíferos para o rio São Francisco, descrita por meio da condição de contorno de carga especificada, quanto à remoção de água pelos riachos da bacia, descrita por meio da condição de contorno tipo dreno, forneceram resultados inferiores aos estimados ou observados, mas dentro da mesma ordem de grandeza. É preciso ter em mente que parte dessa diferença deve ser desconsiderada, pois se deve à contribuição do escoamento superficial para a vazão dos riachos, aspecto não previsto através do modelo utilizado, que envolve somente a quantificação do fluxo subterrâneo que ocorre na bacia. 


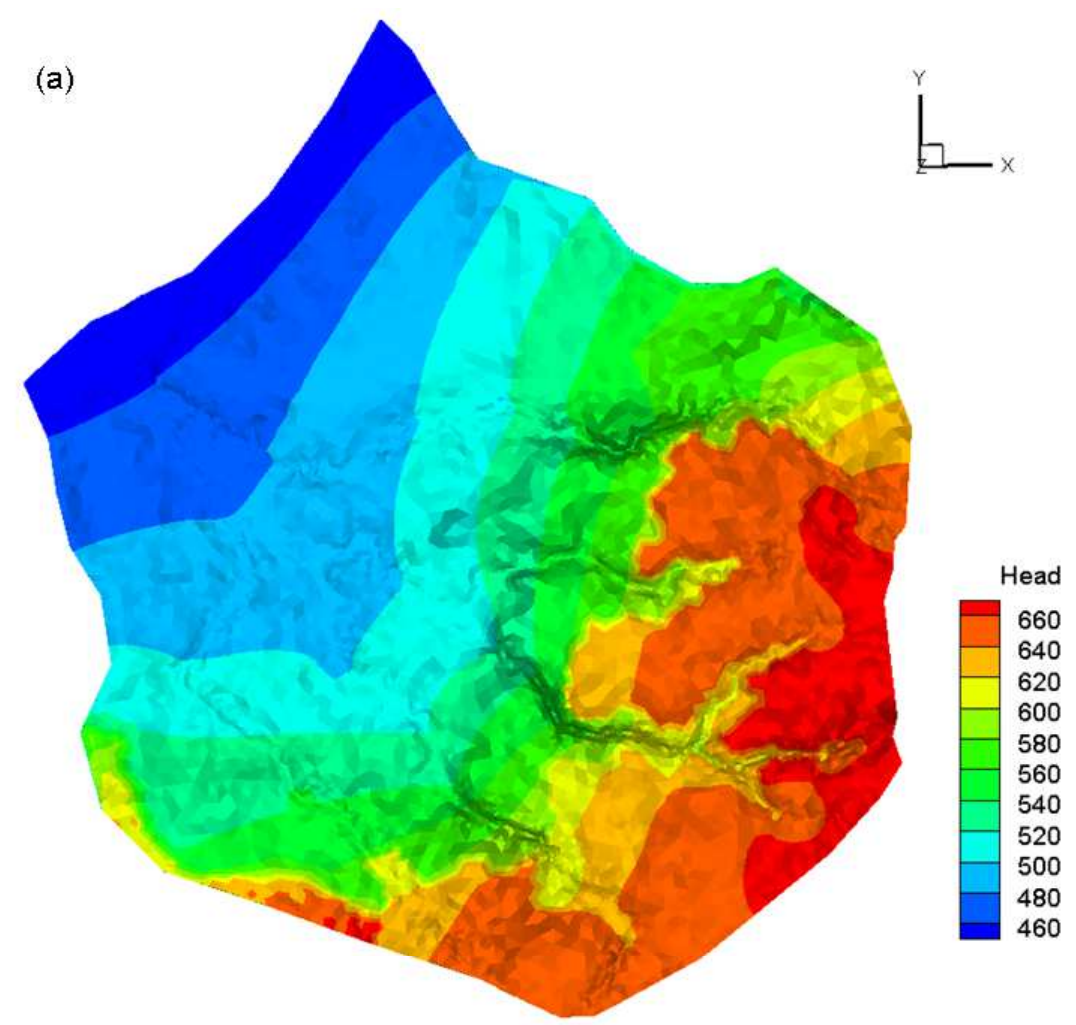

(b)

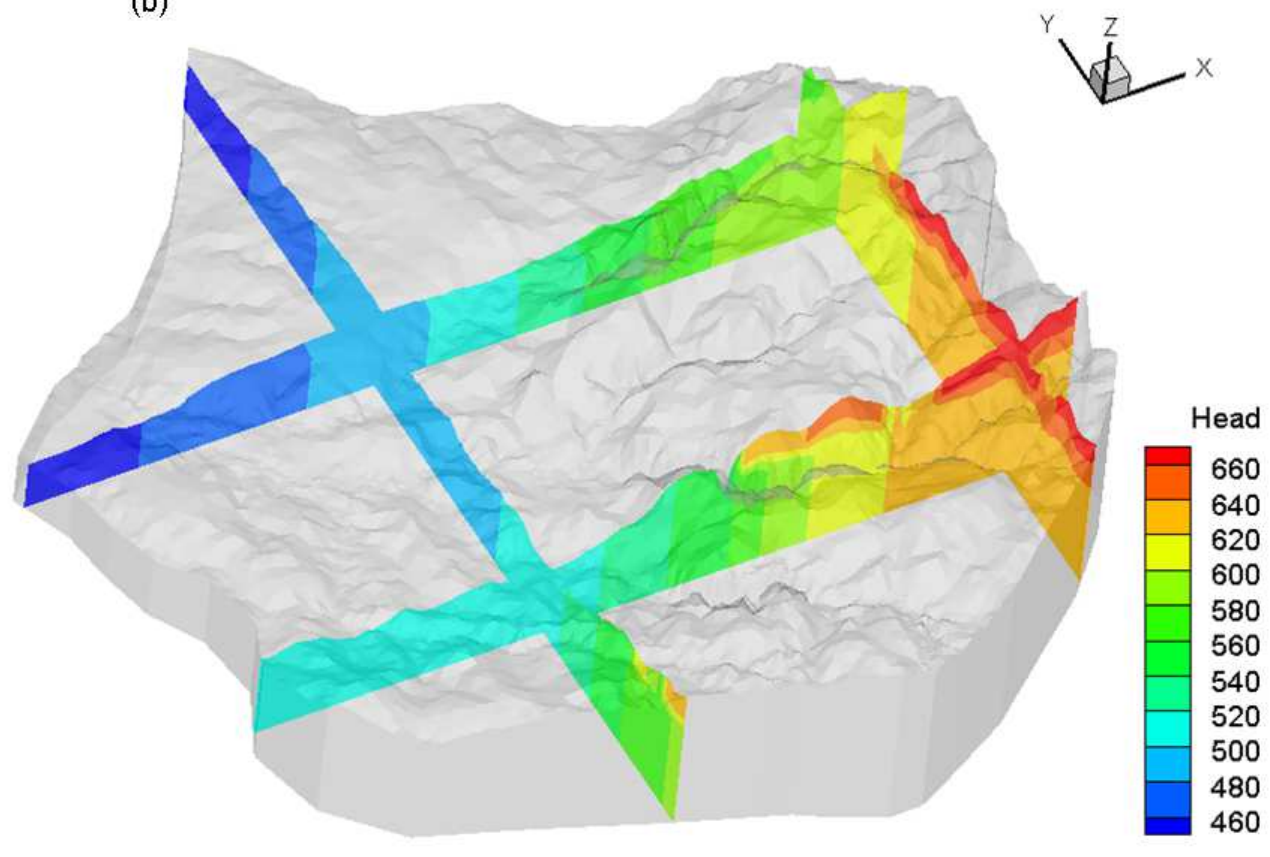

Figura 8 - Resultado do modelo em regime permanente (valores em metros).

Figure 8 - Steady-state model results (values in meters). 


\section{CONCLUSÕES}

O modelo HydroGeoSphere, utilizado para a elaboração do modelo de fluxo em regime permanente dos aquíferos cárstico-fissurais da bacia do riacho Mocambo, São Francisco, MG, mostrou ser robusto e eficiente. Apesar de algumas dificuldades na preparação dos dados de entrada, as ferramentas disponíveis para auxiliar o processo, tal como o programa Grid Builder, se mostraram suficientes para a tarefa. É um modelo que exige um grau um pouco mais elevado de esforço na entrada e saída de dados, mas isso é compensado pela sua versatilidade e robustez.

A partir dos bons resultados de calibração obtidos, pode-se concluir que o modelo de fluxo em regime permanente elaborado para a área representa, com bom grau de confiança, o fluxo subterrâneo observado na bacia do riacho Mocambo ao fim do período chuvoso. O formato das curvas potenciométricas calculadas pelo modelo reproduzem o mapa potenciométrico elaborado a partir dos dados de carga hidráulica medidos nos poços. Os valores gerais calibrados de condutividade hidráulica foram de $6.10^{-2}, 8.10^{-6}$ e $1.10^{-2} \mathrm{~m} / \mathrm{h}$ para o aquífero carbonático superior, o aquitardo e o aquífero carbonático inferior, respectivamente. A recarga principal foi aplicada no topo do aquífero carbonático superior com taxa correspondente a $35 \%$ do excedente hídrico.
Os erros de calibração inerentes ao modelo apontam na direção de cargas hidráulicas mais elevadas (erro médio quadrático de $3 \mathrm{~m}$ ) e descargas ao rio São Francisco e aos córregos subdimensionadas e, consequentemente, de recarga também subdimensionada. As diferenças entre os dados observados e calculados pelo modelo podem estar relacionadas com as incertezas do modelo de fluxo conceitual adotado, como, por exemplo, riachos que podem localmente funcionar como áreas de recarga preferencial, e nas heterogeneidades inerentes a um sistema cárstico-fissural.

Por meio da elaboração do modelo numérico de fluxo, pôde-se constatar que é possível simular o sistema de fluxo subterrâneo cársticofissural através da abordagem de meio poroso equivalente, mesmo sem um conhecimento detalhado dos sistemas de fraturamento e condutos, desde que haja um comportamento geral do sistema de acordo com o esperado para um sistema poroso, sendo que as eventuais inconsistências sejam apenas locais. Mesmo assim, é preciso ponderar que o modelo deve ser visto como indicativo de comportamento e quantificação dos fluxos em uma escala mais ampla e que valores pontuais estimados pelo modelo podem não reproduzir exatamente valores observados locais.

\section{AGRADECIMENTOS}

Os autores agradecem o apoio financeiro do CNPq (Processos nº. 577074/2008-3 e 201236/20095) e aos professores da Universidade de Waterloo, Canadá, R. Aravena, pelas discussões sobre isotopia, e R.G. McLaren e E.A. Sudicky, pela permissão para uso acadêmico do modelo HydroGeoSphere e pelo suporte técnico.

\section{REFERÊNCIAS}

AGENCIA NACIONAL DE AGUAS. Sistema de Informações Hidrológicas: Estação 1544020. Disponível em: <http://hidroweb.ana.gov.br> Acesso em: outubro/2010.

AGENCIA NACIONAL DE AGUAS. Sistema de Informações Hidrológicas: Estação 44200000. Disponível em: $<$ http://hidroweb.ana.gov.br> Acesso em: janeiro/2012.

BARRET, M.E., CHARBENEAU, R.J. A parsimonious model for simulating flow in a karst aquifer. Journal of Hydrology, v.196, p. 47-65, 1997.
BRUNNER, P., SIMMONS, C.T. HydroGeoSphere: A fully integrated, physically based hydrological model, Ground Water, v.50, n.2, p. 170-176, 2012.

DARDENNE, M.A. Síntese sobre a estratigrafia do Grupo Bambuí no Brasil Central. In: Anais do Congresso Brasileiro de Geologia, v.2, p. 597-610, 1978.

DEPARTAMENTO NACIONAL DE PRODUÇÃO MINERAL. Projeto RADAMBRASIL, Levantamento de Recursos Naturais, v. 29, Folha SD.23 Brasília, 1982. 660 p. 
FERRARI, J.A., KARMANN, I. Comportamento hidrodinâmico de sistemas cársticos na bacia do rio Betari, Município de Iporanga - SP, Geologia USP Série Científica, v.8 n.1, p. $1-13,2008$.

FREEZE, R.A., CHERRY, J.A. Groundwater, Englewood Cliffs, N.J.: Prentice-Hall International, 1979. 604 p.

FREIRE, A. P. S., CASTRO, R. E. L. Mapeamento geológico na sub-bacia hidrográfica do riacho mocambo com ênfase nas ocorrências de fluorita e sua relação com as anomalias de fluoreto na água subterrânea no Município de São Francisco. Relatório de Trabalho Final de Graduação, Instituto de Geociências, Universidade Federal de Minas Gerais, 2003. 94 p.

GONDWE B.R.N., MEREDIZ-ALONSO, G. BAUERGOTTWEIN, P. The influence of conceptual model uncertainty on management decisions for a groundwater-dependent ecosystem in karst. Journal of Hydrology, v.400, p. 24-40, 2011.

INSTITUTO NACIONAL DE PESQUISAS ESPACIAIS. Banco de Dados Geomorfométricos do Brasil. Disponível em: <http://www.dsr.inpe.br/topodata $>$ Acesso em: setembro/2011.

INTERNATIONAL ATOMIC ENERGY AGENCY. Environmental isotopes in the hydrological cycle, principles and applications. Paris: UNESCO/IAEA 2001. (Series, IHPV, n. 39).

MARQUES, G.F., COTA, S., BRAGA Jr., P.V., VELÁSQUEZ, L.M., RODRIGUES, P., DE PAULA, R.S. Hydrodynamic characterization of a karst aquifer in the Brazilian semiarid region with time series analysis of hydrology data. In: 2011 World Environmental \& Water Resources Congress: Bearing knowledge for sustainability. Palm Springs, 2011a.

MARQUES, G.F., COTA, S.D.S., MIRANDA, M.P., RODRIGUES, P.C.H. Avaliação de resposta em um aquífero karst com emprego de função de correlação cruzada. In: II Congresso Internacional de Meio Ambiente Subterrâneo, São Paulo. 2011b.

McDONALD, M.G., HARBAUGH, A.W. A modular threedimensional finite-difference ground water flow model. Reston: U.S. Geological Survey, 1988. (Report 83-875).

McLAREN, R.G. Grid Builder: A pre-processor for 2-D, triangular element, finite element programs, Waterloo: University of Waterloo, 2009. 93p.

OLIVEIRA, F.M., MARQUES, G.F., VELASQUEZ, L.N.M. Estudo do planejamento de fontes de produção de água subterrânea em área com alta incidência de flúor natural. In: SIMPÓSIO BRASILEIRO DE RECURSOS HÍDRICOS, 17, 2007. Campo Grande. Anais... São Paulo: ABRH, 2007.
PANAGOPOULOS, G., LAMBRAKIS, N. The contribution of time series analysis to the study of the hydrodynamic characteristics of the karst systems: Application on two typical karst aquifers of Greece (Trifilia, Almyros Crete). Journal of Hydrology v. 329, n. 3-4, p. 368-376, 2006.

PATRUS, M.L.R.A. SANTOS, A.C.S DOS, FIGUEIREDO, V.L.S., MATOS, A.R., MENEZES, I.C.R. Parcela mineira da bacia do rio São Francisco: caracterização hidroclimática e avaliação dos recursos hídricos de superfície. In: PINTO, C.P e NETO, M.A.M. (Ed). Bacia do São Francisco: Geologia e Recursos Naturais. Belo Horizonte: SBG-MG, p. 285-326, 2001.

PINTO, C.P e NETO, M.A.M. (Ed). Bacia do São Francisco: Geologia e Recursos Naturais. Belo Horizonte: SBG-MG, 2001. 349p.

QUINN, J.J., TOMASKO, D., KUIPER, J.A. Modeling complex flow in a karst aquifer. Sedimentary Geology, n.184, p. 343-351, 2006.

SCANLON, B.R., MACE, R.E., BARRET, M.E., SMITH, B. Can we simulate regional groundwater flow in a karst system using equivalent porous media models? Case study, Barton Springs Edwards aquifer, USA. Journal of Hydrology, v.276, p. $137-158,2003$.

THERRIEN, R., MCLAREN, R.G., SUDICKY, E.A. HydroGeoSphere: A three-dimensional numerical model describing fully-integrated subsurface and surface flow and solute transport. Groundwater Simulations Group, Draft (March, 4, 2009), 2009. 392p.

THORNTHWAITE, C. W., MATHER, J.R. The water balance, Publications in Climatology, v.8, p. 1-104, 1955

VELÁSQUEZ, L.N.M.; FANTINEL, L.M.; COSTA, W.D.; UHLEIN, A.; FERREIRA, E.F.E.; CASTILHO, L.S.; PAIXÃO, H.H. Origem do flúor na água subterrânea e sua relação com os casos de fluorose dental no município de São Francisco, Minas Gerais. Belo Horizonte: Fapemig Relatório CRA 294/99, 2003. 138p.

WHITE, W.B. A brief history of karst hydrogeology: contributions of the NSS. Journal of Cave and Karst Studies, v.69, n.1, p. 13-26, 2007.

WHITE, W.B. Conceptual models for carbonate aquifers. Ground Water, v.50, n.2, p.180-186, 2012. 